\title{
Comparison of the efficiency of photoionization at atmospheric pressure and electrospray ionization on the example of some aflatoxins and trichothecenes
}

\author{
(C) Aisylu Z. Mukharlyamova, ${ }^{{ }^{+}}$Alexandr M. Saifutdinov, Elvira R. Rakhmetova, \\ Aygul G. Mukhammetshina, and Igor M. Fitsev \\ Federal Center for Toxicological, Radiation and Biological Safety (FSBSI «FCTRBS-RRVI»). \\ Nauchny Gorodok-2. Kazan, 420075. Republic of Tatarstan.Russia.E-mail: fitzev@mail.ru
}

\begin{abstract}
*Supervising author; ${ }^{+}$Corresponding author Keywords: aflatoxin $\mathrm{B}_{1}, \mathrm{~T}-2$ toxin, mass spectrometric detection, electrospray, photoionization.
\end{abstract}

\begin{abstract}
The article presents the results of comparing the effectiveness of modern ionization methods used in chromatomass spectrometric analysis: photoionization at atmospheric pressure (APPI) and electrospray ionization (ESI) for the determination of aflatoxin $\mathrm{B}_{1}$ and $\mathrm{T}-2$ toxins related to the main natural pollutants of agricultural feed, food raw materials and food products.

Aflatoxin $B_{1}$ is a member of the aflatoxin family, which in their chemical structure are derivatives of substituted coumarins or furocoumarins. The peculiarity of aflatoxins is that in the process of technological or culinary processing, they are practically not destroyed, while being the strongest hepatocancerogens that cause irreversible liver damage.

T-2 toxin refers to trichothecene mycotoxins, in the structure of which there is a trichothecene ring containing a multiple bond and an epoxy group. Most trichothecene mycotoxins are slightly toxic compounds, but T-2 toxin is deadly, having a negative effect on immunocompetent organs, hematopoietic organs, and the gastrointestinal tract, increasing the risk of internal hemorrhage.

Due to the impossibility of preventing contamination of agricultural feed, food raw materials and food products with mycotoxins, their strict control is necessary. Chromatomass spectrometry is one of the methods that provide high sensitivity and reliability for the determination of mycotoxins

Methods of ionization sources, such as electrospray and photoionization at atmospheric pressure during mass spectrometric detection of mycotoxins by high-performance liquid chromatography (HPLC-MS/MS), are evaluated. In order to increase the sensitivity of the determinations, the optimal conditions of the quadrupole-time-of-flight mass spectrometric detector were selected and the maximum intensity responses of the analytes were obtained. During the experiment, it was found that the intensity of the signal with a photoionization source obtained by analyzing the T-2 toxin is higher than the signal obtained by using an electrospray ionization source.
\end{abstract}

\section{References}

[1] V.G. Amelin, A.A. Timofeev. Identification and determination of mikotoxins and food additives in feed by HPLC-high resolution time-f-flight mass spectrometry. J. Analtt. Chem. 2016. Vol.71. No.4. P.410417. (russian)

[2] J. Zhou, L. Tang, J.-Sh. Wang. Assessment of the adverse impacts of aflatoxin B1 on gut-microbiota dependent metabolism in F344 rats Chemosphere. 2019. Vol.217. No.1. P.618-628.

[3] I.M. Fitsev, O.V. Shlyamina, A.Z. Mukharlyamova, S.L. Mokhtarova, E.R. Rakhmetova, A.G.

Mukhammetshina, and Zh.R. Nasybullina. Gas chromatography-mass spectrometry screening persistent organic pollutant in environmental monitoring of vital activity objects. Butlerov Communications. 2020. Vol.62. No.6. P.89-99. DOI: 10.37952/ROI-jbc-01/20-62-6-89

[4] F. Kilicel, H.S. Karapinar, A.Cimen. Quantitation of aflatoxins in food materials using HPLC-FLD method Science Journal of Analytical Chemistry. 2017. Vol.5. No.6. P.90-97.

[5] V.M.T. Lattanzio, M. Solfrizzo, S. Powers. Simultaneous determination of aflatoxins, ochratoxin A and Fusarium toxins in maize by liquid chromatography/tandem mass spectrometry after multitoxinimmunoaffinity cleanup. Rapid Commun. Mass Spectrom. 2007. Vol.21. P.3253-3261.

[6] G.J. Patti, O. Yanes, G. Siuzdak. Metabolomics: the apogee of the omictriology. Nat. Rev. Mol. Cell Biol. 2012. Vol.13. P.263-269.

Kazan. The Republic of Tatarstan. Russia. (C) Butlerov Communications. 2020. Vol.64. No.12. 
[7] R. Ramautar, R. Berger, J. van der Greef, T. Hankemeier. Human metabolomics: strategies to understand biology. Curr. Opin. Chem. Biol. 2013. Vol.17. P.841-846.

[8] J.H. Wang, J. Byun, S. Pennathur. Analytical approaches to metabolomics and applications to systems biology. Semin. Nephrol. 2010. Vol.30. P.500-511.

[9] X. Cao, X. Li, J. Li, Y. Niu, L. Shi, Z. Fang, T. Zhang, H. Ding. Quantitative determination of carcinogenic mycotoxins in human and animal biological matrices and animal-derived foods using multi-mycotoxin and analyte-specific high performance liquid chromatography-tandem mass spectrometric methods. Journal of Chromatography B. 2018. Vol.1073. P.191-200.

[10] D. Touboul. Is methanol a dopant under atmospheric pressure photoionization conditions? Eur. J. Mass Spec. 2019. Vol.25. No.2. P.208-211. 